\title{
Traumatic retained hemothorax: is it time for video assisted thoracoscopic surgery
}

\author{
Mayank Badkur ${ }^{1 *}$, Suruthi Baskaran', Satya Prakash'1, Lalit Kishore², Mahendra Lodha1, \\ Mahaveer Rodha ${ }^{1}$, Ramkaran Chaudhary ${ }^{1}$, Ashok Puranik ${ }^{1}$
}

${ }^{1}$ Department of General Surgery, All India Institute of Medical Sciences, Jodhpur, Rajasthan India
${ }^{2}$ Department of General Surgery, Dr. S. N. Medical College, Jodhpur, Rajasthan, India

Received: 12 August 2020

Accepted: 10 October 2020

*Correspondence:

Dr. Mayank Badkur,

E-mail: drmayankbadkur@gmail.com

Copyright: ( $)$ the author(s), publisher and licensee Medip Academy. This is an open-access article distributed under the terms of the Creative Commons Attribution Non-Commercial License, which permits unrestricted non-commercial use, distribution, and reproduction in any medium, provided the original work is properly cited.

\begin{abstract}
Thoracic trauma is a significant cause of morbidity and mortality, if not treated promptly. $80 \%$ to $85 \%$ of chest injuries can be treated with chest tube insertion alone. However, in about four to $20 \%$ of population, there is incomplete clearance of hemothorax following tube insertion and can lead to a condition called retained hemothorax. The purpose of this review is to establish the role and effectiveness of Video assisted thoracoscopic surgery (VATS) in successful evacuation of retained hemothorax following blunt thoracic trauma. Relevant articles from databases like Pubmed, Google scholar, Medline and Cochrane library were included. A retained hemothorax is defined as the persistence of residual clots in the pleural cavity, which is radiologically evident, 72 hours following initial tube thoracostomy. The various options to manage this condition include observation, insertion of second thoracostomy tube, intrapleural fibrinolytic, VATS or thoracotomy. Based on review of existing studies, VATS evacuation was found to have shorter hospital stay, lesser costs and shorter duration of tube drainage. There was also lesser rate of conversion to thoracotomy as compared to other methods and fewer complications like fibrothorax and empyema. In hemodynamically unstable patients, which is a contraindication to VATS, use of intrapleural fibrinolytics like streptokinase may be considered as an alternative option to provide clearance of the retained hemothorax. Retained hemothorax, when encountered following thoracic trauma, can be effectively managed by VATS. The decision to use VATS for hemothorax evacuation should be made promptly for maximum results, especially within three to seven days following trauma.
\end{abstract}

Keywords: Hemothorax, Retained hemothorax, Video assisted thoracoscopic surgery, Thoracostomy, Thoracic trauma

\section{INTRODUCTION}

Thoracic trauma is a significant cause of morbidity and mortality, if not treated promptly. ${ }^{1}$ In trauma patients worldwide, more than $15 \%$ of injuries are due to blunt chest trauma. ${ }^{2}$ Penetrating chest trauma represents a separate entity, which is relatively less common but more deadly than blunt thoracic trauma. The most common mechanism of blunt chest trauma are motor vehicle accidents, followed by falls. The problems following blunt thoracic trauma include tension pneumothorax, massive hemothorax, pulmonary contusions, multiple rib fractures, tracheobronchial injuries, major vascular injuries, diaphragmatic injuries etc. of particular interest is traumatic hemothorax, wherein the usual line of management is prompt insertion of thoracostomy tube. ${ }^{1}$ $80 \%$ to $85 \%$ of chest injuries can be treated with chest tube insertion alone. ${ }^{3}$ However, in about four to $20 \%$ of population, there is incomplete clearance of hemothorax following tube insertion and can lead to a condition called retained hemothorax. ${ }^{4}$ The complications of retained hemothorax include fibrothorax and empyema. ${ }^{5}$ The management of retained hemothorax can be done in multiple ways like evacuation with Video assisted thoracoscopic surgery (VATS), instillation of intrapleural fibrinolytics or even thoracotomy. ${ }^{6}$ The purpose of this 
review is to establish the role and effectiveness of VATS in successful evacuation of retained hemothorax following blunt thoracic trauma.

\section{METHODS}

All relevant articles were searched from databases like PubMed, Google scholar, Medline, Cochrane library. These included various cohort studies, case control studies, randomized control trials and retrospective reviews on the role of VATS in cases of traumatic retained hemothorax. All articles which described VATS following trauma without preliminary insertion of tube thoracostomy were excluded.

\section{DISCUSSION}

\section{Retained hemothorax}

A retained hemothorax is defined as the persistence of residual clots in the pleural cavity, which is radiologically evident, 72 hours following initial tube thoracostomy. ${ }^{7}$ The amount retained can range from less than $300 \mathrm{ml}$ to more than $500 \mathrm{ml}$. Following trauma, a chest tube is inserted immediately to evacuate hemothorax. Usually, most hemothorax get absorbed spontaneously. ${ }^{8}$ In four$20 \%$ of population, it may not resolve.

The risk factors for development of retained hemothorax include presence of bilateral thoracic injuries, need for intubation on the day of admission and higher Injury severity score (ISS). ${ }^{9}$ High initial output from chest tube, number and duration of chest tube drainage also determine the risk for retained hemothorax. However, the position of tube relative to lung parenchyma or high chest tube placement did not determine the need for secondary intervention. ${ }^{10}$ Kugler et al showed that irrigation of pleural cavity with $1 \mathrm{~L}$ warmed sterile saline during the time of insertion of thoracostomy tube lowered the requirement of secondary intervention. ${ }^{11}$ In a retrospective review by Bilello et al, it was observed that occult hemothorax with size $\geq 1.5 \mathrm{~cm}$ on Computer tomography (CT) were 4 times more likely to require intervention than those with size $<1.5 \mathrm{~cm} .^{12}$

Some of the retained hemothorax may progress to complications like fibrothorax or empyema. The residual clot in the pleural cavity promotes formation of adhesions, which restricts the lung expansion, leading to trapped lung. In a study by Sinha et al, this complication rate for fibrothorax and empyema following small hemothorax was found to be $3.3 \%$ (8). The risk factors for development of empyema include presence of rib fractures, ISS $\geq 25$, need for additional therapeutic interventions. ${ }^{13}$

Both plain chest radiograph and CT can be used to evaluate for retained hemothorax, 48 to 72 hours following trauma. Chest X-ray is simpler to perform, has lesser radiation exposure, however it cannot quantify the amount of hemothorax that is retained nor can it identify parenchymal injuries like pulmonary contusions and pneumonia. ${ }^{14}$ Sonography of chest has a sensitivity of $76 \%$ and specificity of $100 \%$ in detecting retained hemothorax and differentiating it from underlying pulmonary contusions or pneumonia, the only disadvantage being high operatordependence. ${ }^{4} \mathrm{CT}$, despite higher radiation exposure and increased costs, has the advantage that it can quantify the amount of blood clot retained in the pleural cavity, the presence of underlying lung contusions or pneumonia. ${ }^{15}$ Thus, CT is considered as gold standard for diagnosis of retained hemothorax in some studies. ${ }^{4}$ However, in a study by Morrison et al, CT chest was not considered as an essential step before performing VATS, if significant collection was noted on Chest X-ray, three days following trauma. $^{16}$

\section{Management}

A patient of trauma diagnosed to have hemothorax, usually requires placement of a thoracostomy tube of larger size via the fifth intercostal space, just anterior to mid-axillary line, to allow for adequate drainage of the collected blood, except in case of very small hemothorax. A massive hemothorax is defined as spontaneous evacuation of more than $1.5 \mathrm{~L}$ of blood or drainage of more than $200 \mathrm{ml} /$ hour over last 2-4 hours following insertion of thoracostomy tube. ${ }^{1,7}$ In case of massive hemothorax or if the patient is hemodynamically unstable, then there is a need for urgent thoracotomy and exploration.

In hemothorax which is not massive, after insertion of thoracostomy tube, if the radiographs (chest $\mathrm{x}$ ray or CT) done 48 to 72 hours after trauma, reveal residual clots in pleural cavity, there comes a necessity to manage the retained hemothorax to avoid complications. The various options include- observation, insertion of second thoracostomy tube, intrapleural fibrinolytic, VATS or thoracotomy.

Based on a prospective trial for American association for the surgery of trauma (AAST) by DuBose et al, about $25 \%$ of patients were managed successfully by observation alone. The strongest predictor for successful observation was volume of retained hemothorax $<300 \mathrm{ml} .{ }^{13}$ The other option for management of retained hemothorax is insertion of a second thoracostomy tube. In a prospective randomized study by Meyer et al, the enrolled patients were divided into two groups- one in which a second tube was inserted and the other group underwent VATS evacuation. Comparison between the two groups showed that VATS evacuation led to shorter hospital stay, lesser costs and shorter duration of tube drainage. ${ }^{5} \mathrm{~A}$ similar study comparing two groups, VATS Vs reinsertion of chest tube showed longer duration of stay, increased risk of empyema (20\%) and increased wound infection in the latter group. ${ }^{17}$ Thus, insertion of second thoracostomy tube only delayed or complicated appropriate management of retained hemothorax in most cases. 
Intrapleural administration of fibrinolytics like streptokinase, urokinase, tissue plasminogen activators like alteplase also provide a valuable option in the management of retained hemothorax. In a review by Hendriksen et al, lytic therapy led to avoidance of surgery in $87 \%$ of cases. ${ }^{18}$ Also, intrapleural alteplase showed $80 \%$ success rate with $7 \%$ bleeding rate, with higher doses and volumes required for retained hemothorax. ${ }^{19}$ However, in a retrospective study comparing use of streptokinase to VATS for evacuation of retained hemothorax, eight out of 31 cases in which streptokinase was used, failed to show complete radiological improvement and three cases developed empyema, whereas, only four out of 34 patients who underwent VATS showed incomplete radiological improvement and there was no empyema. ${ }^{6}$

\section{VATS}

Hans Christian Jacobæus, first examined the thoracic cavity of a tubercular patient using a cystoscope in 1910 , following which Branco applied thoracoscopy to trauma patients in the year $1946 .{ }^{7}$ With the advent of minimally invasive surgery, the use of VATS has grown multi-fold, especially in thoracic trauma. Some of the well-known indications include retained hemothorax, persistent pneumothorax, repair of lung lacerations, control of intrathoracic bleeding like intercostal arteries, diaphragmatic injuries, oesophageal, tracheobronchial injuries, traumatic chylothorax etc. ${ }^{20}$

In order to perform VATS, patient is placed in lateral position with the diseased lung up and ipsilateral arm abducted $90^{\circ}$ at shoulder. A double lumen endotracheal tube is placed in order to ensure single lung ventilation. This aids in visualizing the pleural cavity without difficulty, owing to collapse of ipsilateral lung. Camera ports and working ports are placed based on ergonomics of the surgeon. Adhesions are removed by blunt dissection or energy devices like electrocautery. All clotted blood is removed using a suction-irrigation catheter and entire pleural cavity is inspected for additional injuries like lung laceration or bleeding intercostal arteries. Other techniques like uniportal VATS involves using a 1.5 to 2.5 $\mathrm{cm}$ incision in the 4th to 6th intercostal space alone posterior axillary line to access the pleural cavity. ${ }^{21}$

\section{Ideal time to perform VATS}

Depending on the time-lapsed between trauma and decision to VATS, there may be difficulty in successful evacuation of retained hemothorax. ${ }^{22}$ The ideal time to perform VATS following thoracic trauma for evacuation of retained hemothorax has been a point of debate. However, most studies show the advantage of performing VATS early (within 7 days) over delayed. Abolhoda et al reported successful evacuation in 12 out of 16 patients, when VATS was performed within seven days post-injury, with the added advantage of ruling out diaphragmatic injuries in three patients. Conversion to thoracotomy occurred in four cases in view of suboptimal single lung ventilation or severe pleural inflammatory reaction. ${ }^{23}$ In a retrospective case series of 81 patients, Fabbrucci et al recommended use of VATS 48 hours from trauma, in cases of uncontrolled air leak or blood loss. This led to shorter hospital stay and decreased costs. ${ }^{24} \mathrm{~A}$ similar retrospective study showed lesser conversion to thoracotomy (8\%) when VATS was performed within five days of trauma as compared to more than five days $(29.4 \%)$ following trauma. ${ }^{25}$ In another study, $80 \%$ of patients required VATS for evacuation of retained clots and $20 \%$ of cases were converted to thoracotomy due to dense adhesions, without any reference to time of trauma. ${ }^{26}$ When VATS was performed seven days after trauma, there was increased incidence of infection, Intensive care unit (ICU) stay, ventilator requirement and duration of chest tube drainage. ${ }^{27}$ In case of patients with head trauma, not severe to require a craniotomy, associated with thoracic injury, it was found that VATS can be performed effectively and safely with the advantage of shorter hospital stay and lesser infection when done within 4 days of trauma. ${ }^{28}$ Thus, earlier the VATS, better is the success rate of evacuation and shorter is the hospital stay.

\section{Additional uses of VATS}

Lung lacerations identified during time of VATS for hemothorax evacuation can be successfully repaired at the same setting. In a prospective cohort study, the group which underwent VATS evacuation with repair of lung laceration has shorted duration of chest drain, shorter ICU and ventilator requirement as compared to the group which underwent only evacuation. ${ }^{29}$

Fixation of ribs is a controversial topic in management of thoracic trauma. In a prospective cohort study by Lin et al, VATS guided fixation of displaced ribs was done along with evacuation of retained hemothorax. This showed a decrease in ventilator dependence, lower occurrence of persistent air leak (>5 days) and lesser requirement of analgesics. $^{30}$

VATS is a useful resource for detection and management of diaphragmatic injuries. It has a sensitivity of $71.5 \%$ and specificity of $75 \%$ in detection of diaphragmatic lacerations. ${ }^{31}$ These lacerations have also been repaired thoracoscopically in several cases. VATS is also found to be helpful for retrieval of foreign bodies from thoracic cavity. ${ }^{32}$

\section{Contraindications to VATS}

Contraindications to VATS include hemodynamic instability, massive hemothorax, inability to sustain single lung ventilation owing to previous surgery, adhesions, or severe COPD (chronic obstructive pulmonary disease). In such cases, use of intrapleural fibrinolytics like streptokinase may be considered as an alternative option to provide clearance of the retained hemothorax. It is especially effective in collections $<300 \mathrm{ml} .{ }^{19}$ 


\section{CONCLUSION}

Retained hemothorax, when encountered following thoracic trauma, can be effectively managed by VATS. The advantage of VATS is mainly due to its minimally invasive nature leading to shorter hospital stay, lesser wound infections and fewer complications like empyema and pneumonia. The decision to use VATS for hemothorax evacuation should be made promptly for maximum results, especially within three to seven days following trauma. However, the surgeon should not hesitate to convert to open thoracotomy in case of difficulty or hemodynamic instability.

Funding: No funding sources Conflict of interest: None declared

Ethical approval: Not required

\section{REFERENCES}

1. Henry S. ATLS advanced trauma life support, student course manual, 10th edition. American college of surgeo. 2018.

2. Chou YP, Lin HL, Wu TC. Video-assisted thoracoscopic surgery for retained hemothorax in blunt chest trauma. Curr Opin Pulm Med. 2015;21(4):393-8.

3. Billeter AT, Druen D, Franklin GA, Smith JW, Wrightson W, Richardson JD. Video-assisted thoracoscopy as an important tool for trauma surgeons: a systematic review. Langenbecks Arch Surg. 2013;398(4):515-23.

4. Bozzay JD, Bradley MJ. Management of posttraumatic retained hemothorax. Trauma. 2019;21(1):14-20.

5. Meyer DM, Jessen ME, Wait MA, Estrera AS. Early Evacuation of Traumatic Retained Hemothoraces Using Thoracoscopy: A Prospective, Randomized Trial. Ann Thorac Surg. 1997;64(5):1396-401.

6. Oğuzkaya F, Akçalı Y, Bilgin M. Videothoracoscopy versus intrapleural streptokinase for management of post traumatic retained haemothorax: a retrospective study of 65 cases. Injury. 2005;36(4):526-9.

7. Casós SR, Richardson JD. Role of thoracoscopy in acute management of chest injury: Curr Opin Crit Care. 2006;12(6):584-9.

8. Sinha P, Sarkar P. Late clotted haemothorax after blunt chest trauma. Emerg Med J. 1998;15(3):18991.

9. Scott MF, Khodaverdian RA, Shaheen JL, Ney AL, Nygaard RM. Predictors of retained hemothorax after trauma and impact on patient outcomes. Eur J Trauma Emerg Surg. 2017;43(2):179-84.

10. Benns MV, Egger ME, Harbrecht BG, Franklin GA, Smith JW, Miller KR, et al. Does chest tube location matter? An analysis of chest tube position and the need for secondary interventions: J Trauma Acute Care Surg. 2015;78(2):386-90.

11. Kugler NW, Carver TW, Milia D, Paul JS. Thoracic irrigation prevents retained hemothorax: A prospective propensity scored analysis. J Trauma Acute Care Surg. 2017;83(6):1136-41.

12. Bilello JF, Davis JW, Lemaster DM. Occult traumatic hemothorax: when can sleeping dogs lie? Am J Surg. 2005;190(6):844-8.

13. DuBose J, Inaba K, Okoye O, Demetriades D, Scalea $\mathrm{T}$, O'Connor J, et al. Development of posttraumatic empyema in patients with retained hemothorax: Results of a prospective, observational AAST study. J Trauma Acute Care Surg. 2012;73(3):752-7.

14. Chardoli M. Accuracy of chest radiography versus chest computed tomography in hemodynamically stable patients with blunt chest trauma. Chin J Traumatol. 2013;16(6):351-4.

15. Kea B, Gamarallage R, Vairamuthu, H, Fortman J, Lunney K, Hendey GW, et al. What is the clinical significance of chest $\mathrm{CT}$ when the chest $\mathrm{X}$-ray result is normal in patients with blunt trauma? Am J Emerg Med. 2013;31(8):1268-73.

16. Morrison CA, Lee TC, Wall MJ, Carrick MM. Use of a Trauma Service Clinical Pathway to Improve Patient Outcomes for Retained Traumatic Hemothorax. World J Surg. 2009;33(9):1851-6.

17. Elkhayat H, Ayyad S, Mohamed AK, Emad M, Farhgaly A. Thoracoscopic evacuation compared with reinsertion of thoracostomy tube in persistent traumatic hemothorax. J Curr Med Res Pract. 2018;3(2):81.

18. Hendriksen BS, Kuroki MT, Armen SB, Reed MF, Taylor MD, Hollenbeak CS. Lytic Therapy for Retained Traumatic Hemothorax. Chest. 2019;155(4):805-15.

19. Holsen MR, Tameron AM, Evans DC, Thompson M. Intrapleural Tissue Plasminogen Activator for Traumatic Retained Hemothorax. Ann Pharmacother. 2019;53(10):1060-6.

20. Lodhia JV, Konstantinidis K, Papagiannopoulos K. Video-assisted thoracoscopic surgery in trauma: pros and cons. J Thorac Dis. 2019;11(4):1662-7.

21. Sanna S, Bertolaccini L, Brandolini J, Argnani D, Mengozzi M, Pardolesi A, et al. Uniportal videoassisted thoracoscopic surgery in hemothorax. J Vis Surg. 2017;3:126.

22. Ziapour B, Mostafidi E, Sadeghi-Bazargani H, Kabir A, Okereke I. Timing to perform VATS for traumatic-retained hemothorax (a systematic review and meta-analysis). Eur J Trauma Emerg Surg. 2020;46(2):337-46.

23. Abolhoda A. Diagnostic and therapeutic video assisted thoracic surgery (VATS) following chest trauma. Eur J Cardiothorac Surg. 1997;12(3):356-60.

24. Fabbrucci P, Nocentini L, Secci S, Manzoli D, Bruscino A, Fedi $M$, et al. Video-assisted thoracoscopy in the early diagnosis and management of post-traumatic pneumothorax and hemothorax. Surg Endosc. 2008;22(5):1227-31.

25. Smith JW, Franklin GA, Harbrecht BG, Richardson JD. Early VATS For Blunt Chest Trauma: A Management Technique Underutilized By Acute 
Care Surgeons: J Trauma Inj Infect Crit Care. 2011;71(1):102-7.

26. Navsaria PH, Vogel RJ, Nicol AJ. Thoracoscopic evacuation of retained posttraumatic hemothorax. Ann Thorac Surg. 2004;78(1):282-5.

27. Lin HL, Huang WY, Yang C, Chou SM, Chiang HI, Kuo LC, et al. How early should VATS be performed for retained haemothorax in blunt chest trauma? Injury. 2014;45(9):1359-64.

28. Huang FD, Yeh WB, Chen SS, Liu YY, Lu IY, Chou $\mathrm{YP}$, et al. Early Management of Retained Hemothorax in Blunt Head and Chest Trauma. World J Surg. 2018;42(7):2061-6.

29. Chou YP, Kuo LC, Soo KM, Tarng YW, Chiang HI, Huang FD, et al. The role of repairing lung lacerations during video-assisted thoracoscopic surgery evacuations for retained haemothorax caused by blunt chest trauma. Eur J Cardiothorac Surg. 2014;46(1):107-11.

30. Lin HL, Tarng YW, Wu TH, Huang FD, Huang WY, Chou YP. The advantages of adding rib fixations during VATS for retained hemothorax in serious blunt chest trauma - A prospective cohort study. Int J Surg. 2019;65:13-8.

31. Yanık F. The role of VATS in the diagnosis and treatment of diaphragmatic injuries after penetrating thoracic traumas. Turk J Trauma Emerg Surg. 2019. Available from: http://www.tjtes.org/eng/jvi.aspx ?pdir=travma\&pln $\mathrm{g}=$ eng\&un=UTD-02682. Last accessed on $10 \mathrm{July}$ 2020.

32. Manlulu A, Lee T, Thung K, Wong R, Yim A. Current indications and results of VATS in the evaluation and management of hemodynamically stable thoracic injuries. Eur J Cardiothorac Surg. 2004;25(6):1048-53.

Cite this article as: Badkur M, Baskaran S, Prakash S, Kishore L, Lodha M, Rodha M, et al. Traumatic retained hemothorax: is it time for video assisted thoracoscopic surgery. Int Surg J 2020;7:3880-4. 